\title{
Colorectal cancer and its delayed diagnosis: have we improved in the past 25 years?
}

\author{
Carlos Cerdán-Santacruz, Óscar Cano-Valderrama, Sofía Cárdenas-Crespo, Antonio José Torres-García \\ and Javier Cerdán-Miguel
}

Unit of General and Digestive Tract Surgery 2. Hospital Universitario Clínico San Carlos. Madrid, Spain

\begin{abstract}
Objective: to determine the current delay in diagnosing colorectal cancer (CRC) and establish whether there has been any improvement in the past 25 years in the same healthcare setting using the same methods.

Patients and method: 152 patients undergoing surgery at our unit were personally interviewed during their hospital stay to determine the delay incurred for the diagnosis and treatment of their CRC. SPSS software was used for univariate and multivariate analysis of the data obtained.

Results: the study population was comprised of 152 patients of mean age 71 years (SD 10; range 36 to 90 years), 82 men and 70 women (53.9 and $46.1 \%$ respectively; $p>0.05$ ). The diagnostic delay for $\mathrm{CRC}$ at our unit currently runs at 7.28 months despite the fact that in $58 \%$ of patients the disease produced obvious symptoms such as rectal bleeding. Although this delay in diagnosis is reduced over that observed 25 years ago, the difference is statiscally not significant in terms of both doctor-attributed or patient-attributed delay (doctor-attributed delay was 3.28 months in 1985 versus 1.89 at present and patient-attributed delay was 3.18 months versus today's $2.75 ; p>0.05)$. Unlike the situation 25 years ago, no link was detected between diagnostic delay and tumor stage. Paradoxically, stage $\mathrm{D}$ disease was diagnosed earlier (at 5.71 months) than stage A disease (at 11.16 months) $(p<0.05)$

Conclusion: the diagnostic delay for $\mathrm{CRC}$ at our centre is 7.28 months. This delay is excessive for a disease that produces evident symptoms in $90 \%$ of patients. Over the last 25 years little improvement has been noted in the overall delay in diagnosing CRC, although the delay attributed to the care provider has significantly improved. No relationship was detected between diagnostic delay and disease stage upon diagnosis. We feel the high prevalence of $\mathrm{CRC}$, the failure of campaigns to increase awareness of early symptoms and no real improvement in its prognosis justify the introduction of large-scale colonoscopy screening for this disease.
\end{abstract}

Received: 03-01-11.

Accepted: 20-04-11.

Correspondence: Carlos Cerdán Santacruz. Unit of General and Digestive Tract Surgery 2. Hospital Clínico Universitario San Carlos. C/ Profesor Martín Lagos, s/n. 28040 Madrid, Spain.

e-mail: carloscerdansantacruz@hotmail.com
Key words: Colorectal cancer. Diagnostic delay. Prognosis. Screening.

Cerdán-Santacruz C, Cano-Valderrama O, Cárdenas-Crespo S, Torres-García AJ, Cerdán-Miguel J. Colorectal cancer and its delayed diagnosis: have we improved in the past 25 years? Rev Esp Enferm Dig 2011; 103: 458-463.

\section{INTRODUCTION}

Adenocarcinoma of the colon and rectum is one of the most prevalent cancers in western countries (1-4). The clinical course of disease is highly variable and starting symptoms range from vague, non specific symptoms such as diffuse abdominal pain, altered bowel habits and changes in the shape of stools to the more spectacular symptom of rectal bleeding $(5,6)$, which should activate alarm signals in both patient and doctor.

Surprisingly, the prognosis for patients with colorectal cancer (CRC) has hardly changed in the past few decades (7-9) despite considerable advances made in diagnostic tests and treatment. It has been unanimously admitted that the main prognostic factor for this disease is its stage at the moment of diagnosis (9).

Several researchers have tried to correlate tumor stage and thus its prognosis with the delay that exists between the start of symptoms and diagnosis and treatment. Results so far have been varied and contradictory. Thus, some authors conclude that there is correlation between a greater delay and a more advanced tumor stage (10-12), while according to others, this relationship only holds for tumors of the rectum (13-15) and some have been unable to find any relationship at all $(9,16-26)$. 
In 1985 , a study was conducted at our centre (27) in which the diagnostic delay for CRC was addressed according to the whether the delay was patient-attributed, doctorattributed or attributable to the diagnostic tests requested. The present study was designed to compare these results obtained 25 years ago with the current situation.

\section{PATIENTS AND METHODS}

Over the period 2007 to 2009 , we personally interviewed 152 patients admitted to our hospital unit for the surgical treatment of CRC. These interviews were conducted by three attending physicians of our unit and were designed to determine the cumulative delay incurred in the diagnosis and treatment of their CRC. This delay was classified into the categories:

1. Patient-attributed delay: the time elapsed since the patient first noticed evident signs of CRC until the first consultation with the general practitioner.

2. Doctor-attributed delay: this was taken as the time since the first time the GP was consulted to the time any test targeted at diagnosing CRC was requested.

3. Diagnostic delay: the time taken for the tests requested by the GP.

4. Intervention delay: from the time of diagnosis and a complete study of tumor extension until treatment was conducted.

5. Overall delay: the sum of all the above delays.

For the statistical analysis, the data for categories 3 and 4 were considered as a single category designated delay attributed to tests.

Besides this information, data were also collected on variables such as symptoms, tumor site, emergency or elective surgery and its intention (curative, palliative or nonresectable) and anatomopathological tumor stage.

Tumor site was divided into the groups: right colon (including the ascending and transverse colon), the left, or descending, colon, the sigmoid colon and rectum.

For tumor staging, Dukes' classification was used since this was the system used in the 1985 study.

Of all the patients attended at our unit over the period 2007 to 2009,152 were enrolled in this study after excluding: patients in whom it was difficult to undertake an anamnesis, patients re-operated on due to local tumor recurrence

Table I. Relationship between diagnostic delay and tumor site

\begin{tabular}{|c|c|c|c|c|}
\hline Delay & Right colon & Left colon & $\begin{array}{l}\text { Sigmoid } \\
\text { colon }\end{array}$ & Rectum \\
\hline Patient & 1.82 & 1.63 & 2.89 & 3.39 \\
\hline Physician & 3.09 & 1.71 & 1.25 & 1.53 \\
\hline Tests & 1.92 & 3.37 & 2.1 & 3.15 \\
\hline Overall delay & 6.83 & 6.71 & 6.24 & 8.07 \\
\hline
\end{tabular}

who were being followed by us, those with CRC diagnosed in a screening campaign and those refusing to participate in the study.

All data were collected in a database specially designed for this study. Data were compared by ANOVA or a Student's t-test. All tests were performed using the SPSS 15.0 program. The level of significance was set at $\mathrm{p}<0.05$.

\section{RESULTS}

Of the 152 patients included, 6 were diagnosed and underwent surgery on an emergency basis due to intestinal obstruction caused by a stenosing neoplasia in the colon or rectum. In the remaining patients, surgery was elective.

The mean age of the patients was 71 years (SD 10, range $36-90$ years). Eighty two of the patients were men and 70 women (53.9 and $46.1 \%$ respectively; $\mathrm{p}>0.05$ ).

In $90.8 \%$, some type of symptom was observed, among which we would highlight rectal bleeding in $58.6 \%$, altered bowel habits in $35.5 \%$, asthenia in $26.3 \%$ and abdominal pain in $23 \%$. Patients showing no symptoms were not derived from any screening program; most were elderly subjects who during a prolonged hospital stay had been subjected to colonoscopy due to chronic anemia, which produced no recognizable symptoms.

The mean diagnostic delay was 7.28 months (SD 8.55) and means for the different categories were: patient-attributed 2.75, physician-attributed 1.89 and testing delay 2.64 months.

Data on the relationship between delay and tumor site or the possible repercussions of delay on tumor stage are provided in tables I and II, respectively.

Among the tumor sites considered, the rectum was associated with the greatest delay although the difference was not significant. For correlations between tumor stage and diagnostic delay, results were also non significant and paradoxically a reduced diagnostic delay was related to a the more advanced tumor stage, stage $\mathrm{D}$, while stage $\mathrm{A}$ was linked to a greater delay.

It should be mentioned that among the patients with rectal cancer who received neoadjuvant radio-chemotherapy, the anatomopathological study of the specimens revealed tumor sterilization in 4 cases $(10 \%$ of the rectal tumors treated with neoadjuvant radio-chemotherapy).

Table II. Relationship between diagnostic delay and Dukes' tumor stage

\begin{tabular}{lllll}
\hline Delay & $A$ & $B$ & $C$ & $D$ \\
\hline Patient & 5.18 & 0.85 & 4.09 & 1.74 \\
Physician & 2.84 & 3.03 & 0.67 & 1.62 \\
Tests & 3.14 & 2.40 & 2.92 & 2.35 \\
Overall delay & 11.16 & 6.28 & 7.68 & 5.71 \\
\hline
\end{tabular}


Table III. Patient distribution by tumor site and Dukes' stage

\begin{tabular}{|c|c|c|c|c|c|}
\hline & $A$ & B & C & $D$ & Total \\
\hline Right colon & 7 & 13 & 11 & 8 & $\begin{array}{l}39 \\
(26.5 \%)\end{array}$ \\
\hline Left colon & 2 & 4 & 4 & 2 & $\begin{array}{l}12 \\
(8.2 \%)\end{array}$ \\
\hline Sigmoid colon & 3 & 10 & 7 & 10 & $\begin{array}{l}30 \\
(20.4 \%)\end{array}$ \\
\hline Rectum & 13 & 15 & 21 & 17 & $\begin{array}{l}66 \\
(449 \%)\end{array}$ \\
\hline Total & $\begin{array}{l}25 \\
(16.4 \%)\end{array}$ & $\begin{array}{l}42 \\
(27.6 \%)\end{array}$ & $\begin{array}{l}43 \\
(28.3 \%)\end{array}$ & $\begin{array}{l}37 \\
(24.3 \%)\end{array}$ & \\
\hline
\end{tabular}

The numbers of patients assigned to each Dukes' stage by tumor site are provided in table III.

We compared the diagnostic delay recorded with that reported in 1985 in the same healthcare setting and using the same methods. The differences detected are illustrated in figure 1 (A and B), which indicate the changes in delay and Dukes' stages, respectively. The only variable that was significantly modified was physician-attributed delay, which has dropped from 3.28 to 1.89 months. In addition, there has been an increase in the proportion of cases diagnosed at stage $\mathrm{A}$ to the detriment of tumors diagnosed in stage B, with no variation in the number of tumors diagnosed at the more advanced stages $C$ and $D$ over these 25 years.

Finally, the results of our analysis of the relationship between rectal bleeding and diagnostic delay appear in table IV.

\section{DISCUSSION}

The mean diagnostic delay for CRC in our hospital setting was estimated here at 7.28 months. We consider this figure
Table IV. Relationship between rectal bleeding and diagnostic delay

\begin{tabular}{lll}
\hline & Bleeding & No bleeding \\
\hline$<3$ months & $26(29.2 \%)$ & $37(58.7 \%)$ \\
$3-6$ months & $21(23.6 \%)$ & $7(18.4 \%)$ \\
$6-9$ months & $14(15.7 \%)$ & $9(15.1 \%)$ \\
$9-12$ months & $9(10.1 \%)$ & $3(7.9 \%)$ \\
$>12$ months & $19(21.3 \%)$ & $7(11.1 \%)$ \\
\hline
\end{tabular}

excessive for the second most common type of cancer and the leading cause of death in the western world and third cause of death worldwide, second only to lung and stomach cancer (2). However, it is even more surprising than in the past 25 years, despite clear improvements in patient access to medical information (28), diagnostic techniques and their availability, no measures taken have proved efficient for the prevention and/or early diagnosis of CRC, since there has been little change in its diagnostic delay (29-31). These data suggest a need for greater information both for the general public and for primary care providers on the symptoms that should prompt a suspicion of a tumor in the colon or rectum, and of measures to be taken when these symptoms arise.

Some variation was detected in tumor stage on diagnosis when we compared the 1985 data with the present data. However, considering that stages A and B indicate local disease and stages $\mathrm{C}$ and $\mathrm{D}$ indicate advanced disease, no significant variation has been produced over these 25 years.

Whether a patient survives colorectal cancer is closely linked to the extent of disease spread such that the change observed here in tumor stage upon diagnosis would not be expected to translate to a change in overall prognosis.

When we examined the possible relationship between Dukes' tumor stage and diagnostic delay, which in 1985

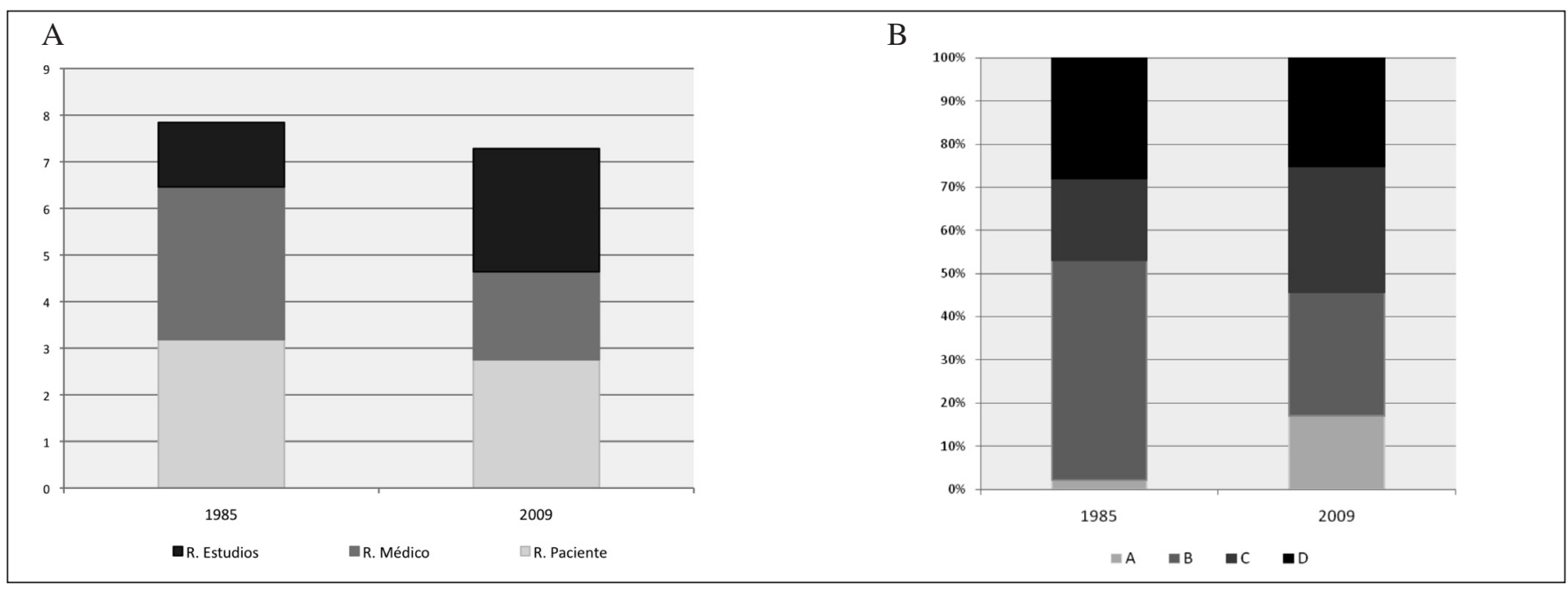

Fig. 1. Differences observed between 1985 and 2009. A. Diagnostic delay in 1985 versus 2009. B. Distributions of Dukes' tumour stages in 1985 versus 2009. 
proved to be significant with a more advanced tumor stage as the diagnostic delay increased (27), no significant differences were observed $(p>0.05)$. This point has been widely disputed in the literature since the results of the many studies that have addressed this issue have been contradictory (9-26). Thus, some authors have reported significant differences while others admit this relationship only for tumors of the rectum and not the colon.

A diagnosis, albeit early, in the symptomatic phase of the disease has so far proved insufficient to improve its prognosis. In contrast, screening to identify patients in an asymptomatic phase does seem to have beneficial impacts and all the strategies tested to date have also proved costeffective (33-36). The benefits of such campaigns besides increasing the number of diagnoses made in less advanced stages of the disease with the consequent repercussions on survival (37-51), also include a reduction in the incidence of CRC $(32,37,52-55)$. Thus, some reports have cited incidence reductions of 75 to $90 \%$ along with savings of the costs arising from disease treatment $(52,56)$.

Besides the link between Dukes' tumor stage and diagnostic delay, in this study we examined the relationship between diagnostic delay and the presence or not of rectal bleeding. It is striking that in our patient cohort, among those with this obvious symptom clearly associated with malignancies of the lower digestive tract, some $70 \%$ did not receive adequate treatment before three months. The most plausible explanation for this is the common misinterpretation of bleeding as that of a benign anorectal condition, mainly hemorrhoids, given the high prevalence of this disease $(9,19)$. The correct interpretation of this symptom could be key if it is eventually demonstrated that a timely diagnosis will mean a less advanced tumor stage and thus a better prognosis.

Our findings point to a need to improve the awareness of both the general and medical (57) population about the need to initiate appropriate tests as quickly as possible in patients with symptoms of CRC to expedite the diagnosis of this disease. Since early diagnosis programs have so far failed to significantly increase the number of patients identified in early disease stages (58-66), it seems that screening campaigns hold greatest promise. In our opinion, the method of choice for such campaigns is colonoscopy $(67,68)$ because of its high sensitivity (close to $100 \%)$, the possibility of removing polyps avoiding their malignant degeneration, its safety, including a minimum acceptable number of complications $(42,69)$, and a high degree of reported patient satisfaction (70).

Thus, a large part of our efforts in the battle against colorectal cancer should focus on implementing widespread screening programs.

\section{CONCLUSIONS}

- In the past 25 years, the delay in diagnosing CRC has hardly varied at all although delays attributable to the GP have significantly improved.
- The diagnostic delay for CRC at our centre is currently 7.28 months, which we consider excessive for a disease that produces symptoms in $90 \%$ of affected patients.

- In elderly patients, the finding of persistent anemia should alert the physician of a need for an endoscopy study.

- Although rectal bleeding is the most frequently reported symptom affecting up to $58 \%$, of patients, its presence does not result in a shortened diagnostic delay.

- We detected no relationship between diagnostic delay and tumor stage although we think there is a need for further work on this issue given the conflictive data available in the literature.

- Given that an early diagnosis and improved prognosis of colorectal cancer should be a clear objective, patient education campaigns should be intensified to increase general awareness of the problem and adherence to screening campaigns. Indeed, such screening campaigns are common practice in some European countries and North America (71-74).

\section{REFERENCES}

1. Jemal A, Siegel R, Xu J, Ward E. Cancer statistics, 2010. CA Cancer J Clin 2010;60;277-300.

2. Bixquet Jiménez M. Early diagnosis of colorectal cancer. Diagnostic delay reduction or rather screening programs? Rev Esp Enferm Dig 2006;98(5):315-21.

3. Ferlay J, Autier P, Borriol M, Heanue M, Colombet M, Boyle P. Estimates of the cancer incidence and mortatlity in Europe 2006. Ann Oncol 2007; 18:581-92.

4. Boyle P and Ferlay J. Cancer incidence and mortality in Europe, 2004. Ann Oncol 2005;16:481-8.

5. Korsgaard M, Pedersen L, Sørensen HT, Laurberg S. Reported symptoms, diagnostic delay and stage of colorectal cancer: a populationbased study in Denmark. Colorectal Dis 2006;8:688-95.

6. Majumdar SR, Fletcher RH, Evans AT. How does colorectal cancer present? Symptoms, duration, and clues to location. Am J Gastroenterol 1999;94:3039-45.

7. Singh S, Morgan MBF, Broughton M, Caffarey S, Topham C, Marks CG. A 10-year prospective audit of outcome of surgical treatment for colorectal carcinoma. Br J Surg 1995;82:1486-90.

8. Greenlee RT, Hill-Harman MB, Murray T, Thun M. Cancer Statistics, 2001. CA Cancer J Clin 2001;51:15-36.

9. Roncoroni L, Pietra N, Violi V, Choua O, Peracchia A. Delay in diagnosis and outcome of colorectal cancer: a prospective study. Eur J Surg Oncol 1999;25:173-8.

10. MacArthur C, Smith A. Factors associated with speed of diagnosis, referral, and treatment in colorectal cancer. J Epidemiol Community Health 1984;38:122-6.

11. Welch CE, Burke JF. Carcinoma of the Colon and Rectum. N Engl J Med 1962;266:211-9.

12 Gilberstein VA. The earlier diagnosis of the adenocarcinoma of the large intestine. Cancer 1971;27:143-9.

13. Iversen LH, Antonsen S, Laurberg S, Lautrup MD. Therapeutic delay reduces survival of rectal cancer but not of colonic cancer. Br J Surg 2009;96:1183-9.

14. Arbman G, Nilsson E, Storgren-Fordell V, Sjodahl R. A short diagnostic delay is more important for rectal cancer than for colonic cancer. Eur J Surg 1996;162:899-904

15. Korsgaard M, Pedersen L, Sørensen HT, Laurberg S. Delay of treatment is associated with advanced stage of rectal cancer but not of colon cancer. Cancer Detect Prev 2006;30:341-6.

16. Irvin TT and Greaney MG. Duration of symptoms and prognosis of carcinoma of the colon and rectum. Gynecology and Obstetrics 1977;144:883-6. 
17. Lim BS, Dennis CR, Gardner B and Newman J. Analysis of survival versus patient and doctor delay of treatment in gastrointestinal cancer. Am J Surg 1974;127:210-4.

18. González-Hermoso F, Pérez-Palma J, Marchena-Gómez J, LorenzoRocha N, Medina-Arana V. Can Early Diagnosis of Symptomatic Colorectal Cancer Improve the Prognosis? World J Surg 2004;28:716-20.

19. Ristvedt SL, Birnbaum EH, Dietz DW, Fleshman JW, Kodner IJ, Read TE. Delayed treatment for rectal cancer. Dis Colon Rectum 2005; 48:1736-41

20. McDermott FT, Hughes ESR, Pihl E, Milne BJ, Price AB. Prognosis in relation to symptom duration in colon cancer. Br J Surg 1981;68:8469 .

21. Holliday HW,Hardcastle JD. Delay in diagnosis and treatment of symptomatic colorectal cancer. Lancet 1979;1:309-11.

22. Gómez-Domínguez E, Trapero-Marugán M, del Pozo AJ, Cantero J, Gisbert JP, Maté J. The colorectal carcinoma prognosis factors. Significance of diagnosis delay. Rev Esp Enferm Dig 2006;98:322-9.

23. Bevis P, Donaldson OW, Card M, Durdey P, Thomas MG, Sylvester $\mathrm{PA}$, et al. The association between referral resource and stage disease in patients with colorectal cancer. Colorectal Dis 2007;10:58-62.

24. Bharucha S, Hughes S, Kenyon V, Anderson ID, Carlson GL, Scott NA. Targets and elective colorectal cancer: outcome and symptom delay at surgical resection. Colorectal Dis 2006;7:169-71.

25. Ramos M, Esteva M, Cabeza E, Llobera J, Ruiz A. Lack of association between diagnostic and therapeutic delay and stage of colorectal cancer. Eur J Cancer 2008;44:510-21.

26. Terhaar sive Droste JS, Oort FA, van der Hulst RWM, Coupé VMH, Craanen ME, Meijer GA, et al. Does delay in diagnosing colorectal cancer in symptomatic patients affect tumor stage and survival? A population-based observational study. BMC Cancer 2010;10:332-42.

27. Cerdán FJ, Díez M, Martín J, de la Morena MT, de Frutos L, Balibrea JL. Relación entre retraso diagnóstico y estadio anatomopatológico en el cáncer colorrectal. Cir Esp 1985;39:651-6.

28. Kassier JP. Patients, physicians and the internet. Health Aff 2000;19 (6):115-23.

29. Langenbach MR, Schmidt J, Neumann J, Zirngibl H. Delay in treatment of colorectal cancer: multifactorial problem. World J Surg 2003;27:304-

30. Harris GJ, Simson JN. Causes of late diagnosis in cases of colorectal cancer seen in a district general hospital over a 2-year period. Ann R Coll Surg Engl 1998;80:296-8

31. Korsgaard M, Pedersen L, Laurberg S. Delay of diagnosis and treatment of colorectal cancer - A population based Danish study. Cancer Detect Prev 2008;32:45-51.

32. Lieberman DA. Cost-effectiveness model for colon cancer screening. Gastroenterology 1995;109:1781-90.

33. Trowbridge B, Burt RW. Colorectal cancer screening. Surg Clin N Am 2002;82:943-57.

34. O Leary BA, Olynyk JK, Neville AM, Platell CF. Cost-effectiveness of colorectal cancer screening: Comparison of community-based flexible sigmoidoscopy with fecal occult blood testing and colonoscopy. J Gastroenterol Hepatol 2004;19:38-47.

35. Frazier LA, Coldiz GA, Fuchs CI, Kuntz KM. Cost-effectiveness of Screening for colorectal cancer in the general population. JAMA 2000;284:1954-61

36. Telford JJ, Levin AR, Sambrook JC, Zou D, Enns RA. The cost-effectiveness of screening for colorectal cancer. CMAJ 2010;182:1307-13.

37. Mandel JS, Bond JH, Church TR, Snover DC, Bradley GM, Schuman LM, et al. Reducing mortality from colorectal cancer by screening for fecal occult blood. N Engl J Med 1993;328:1365-71.

38. Malila N, Olivanen T, Malminiemi O, Hakama M. Test, episode, and programme sensitivities of screening for colorectal cancer as a public health policy in Finland: experimental design. BMJ 2008;337:a2261.

39. Selby J, Friedman GD, Quesenberry CP, Weiss NS. A case-control study of screening sigmoidoscopy and mortality from colorectal cancer. N Engl J Med 1992;326:653-7.

40. Provenzale D, Homan RK, Oddone EZ. Screening colonoscopy in average risk individuals is cost-effective compared with other practices. Am J Gastroenterol 1999;94:2682.

41. Ellul P, Fogden E, Simpson CL, Nickerson CLR, McKaig BC, Swarbrick ET, et al. Downstaging of colorectal cancer by the national bowel cancer screening programme in England: first round data from the first centre. Colorectal Dis 2010;12:420-2.
42. Bokemeyer B, Bock H, Hüppe D, Düffelmeyer M, Rambow A, Tacke $\mathrm{W}$, et al. Screening colonoscopy for colorectal cancer prevention: results from a German online registry on 269000 cases. Eur J Gastroenterol Hepatol 2009;21:650-5.

43. Fujita M, Sugiyama R, Kumanishi Y, Ota J, Haino T, Nakano Y, et al. Evaluation of effectiveness of mass screening for colorectal cancer. World J Surg 1990;14:648-53.

44. Atkin WS, Cook CF, Cuzick J, Edwards R. Single flexible sigmoidoscopy screening to prevent colorectal cancer: baseline findings of a UK multicentre randomized trial. Lancet 2002; 359:1291-300.

45. Hardcastle JS, Chamberlain JO, Robinson MHE, Moss SM, Amar SS, Balfour TW, et al. Randomized controlled trial of faecal-occult-blood screening for colorectal cancer. Lancet 1996;348:1472-7.

46. Lieberman DA, Weiss DG. One-time screening for colorectal cancer with combined fecal occult-blood testing and examination of the distal colon. N Engl J Med 2001;345(8):555-60.

47. Lieberman DA, Weiss DG, Bond JH, Ahnen DJ, Garewal H, Chejfec G. Use of colonoscopy to screen asymptomatic adults for colorectal cancer. N Engl J Med 2000; 343(3):162-8.

48. Selby JV, Friefman GD, Quesenberry CP, Weiss NS. A case-control study of screening sigmoidoscopy and mortality from colorectal cancer N Engl J Med 1992;326:653-7.

49. Jørgensen OD, Kronborg O, Fenger C. A randomized study of screening for colorectal cancer using fasecal occult blood testing: results after 13 years and seven biennial screening rounds. Gut 2002;50:2932.

50. Steele RJC, Kostourou I, McClements P, Watling C, Libby G, Weller $\mathrm{D}$, et al. Effect of repeated invitations on uptake of colorectal cancer screening using faecal occult blood testing: analysis of prevalence and incidence screening. BMJ 2010;341:c5531.

51. Courtier R, Casamitjana M, Macià F, Panadés A, Castells X, Gil MJ, et al. Results of a study on populational colorectal cancer screening. Cir Esp 2009;85:152-7.

52. Chu E. Colorectal cancer screening and early detection. Clinical Colorectal Cancer 2010;2:75-6.

53. Hundt S, Hang U, Brenner $\mathrm{H}$. Comparative evaluation of immunochemical fecal occult blood tests for colorectal adenoma detection. Ann Intern Med 2009;150:162-9.

54. Winawer SJ, Zauber AG, Ho MN, O Brien MJ, Gottlieb LS, Sternberg SS, et al. Prevention of colorectal cancer by colonoscopic polypectomy: the National Polyp Study Workgroup. N Engl J Med 1993;329:197781 .

55. Citarda F, Capocaccia R, Barcherini S, Crespi M. Efficacy in standard clinical practice of colonoscopic polypectomy in reducing colorectal cancer incidence. Gut 2001;48:812-5.

56. Lansdorp-Vogelaar I, van Ballegooijen M, Zauber AG, Habbema JD, Kuipers EJ. Effect of rising chemotherapy cost savings of colorectal cancer screening. J Natl Cancer Inst 2009;101:1412-22.

57. Ruiz-Torrejón A, Ramos-Monserrat M, Llobera-Cánavas J. El medico de atención primaria y el diagnóstico de los pacientes con cáncer. Aten Primaria 2006;37:16-21

58. Navarro M, Binefa G, Blanco I, Guardiola J, Rodríguez-Moranta F, Peris $\mathrm{M}$ et al. Colorectal cancer screening: strategies to select populations with moderate risk for disease. Rev Esp Enferm Dig 2009; 101(12):855-60.

59. Bixquert-Jiménez M. Selective colorectal cancer screening in averagerisk populations. Rev Esp Enferm Dig 2009;101(12):821-9.

60. Allison JE, potter MB. New screening guidelines for colorectal cancer: a practical guide for the primary care physician. Prim Care Clin Office Pract 2009;36:575-602.

61. Geiger TM, Ricciardi R. Screening options and recommendations for colorectal cancer. Clin Colon Rectal Surg 2009;22:209-17.

62. Miser WF. Cancer screening in the primary care setting. Prim Care Clin Office Pract 2007;34:137-67.

63. Mandel JS. Screening of patients at average risk for colon cancer. Med Clin N Am 2005;89:43-59.

64. Mandel JS. Screening for colorectal cancer. Gastroenterol Clin N Am 2008;37:97-115.

65. Advisory Committee on Cancer Prevention. Recommendations on cancer screening in the European Union. European Journal of Cancer 2000;36:1473-8.

66. Miller AB. Implementation of colon cancer screening: techniques, costs, and barriers. Gastroenterol Clin N Am 2008;37:83-95. 
67. WGO/IDCA Internacional para Cáncer Digestivo: tamizaje del cáncer colorrectal. World Gastroenterology Organization 2007.

68. ASGE guideline: colorectal cancer screening and surveillance. Gastrointestinal Endoscopy 2006;63:546-57.

69. Luchtefeld MA, Kim DG. Colonoscopy in the Office Setting is Safe, and Financially Sound... for now. Dis Colon Rectum 2006;49:37782.

70. Chartier L, Arthurs E, Sewitch MJ. Patient satisfaction with colonoscopy: a literature review and pilot study. Can J Gastroenterol 2009; 23(3):203-9.
71. Winawer SJ, Fletcher RH, Miller L, Godlee F, Stolar MH, Mulrow CD, et al. Colorectal Cancer Screening: Clinical Guidelines and Rationale. Gastroenterology 1997;112:594-642.

72. Pox C, Schmiegel W, Classen M. Current status of screening colonoscopy in Europe and in the United States. Endoscopy 2007;39:168-73.

73. Haboubi N. Why screening and who is benefiting? Colorectal Dis 2010;12:395-6

74. Zavoral M, Suchanek S, Zavada F, Dusek L, Muzik J, Seifert B, et al. Colorectal cancer screening in Europe. World J Gastroenterol 2009; 15:5907-15. 